\title{
Historical responsibility for climate change: science and the science-policy interface
}

\author{
Mathias Friman and Gustav Strandberg

\section{Linköping University Post Print}

\section{Tweet}

N.B.: When citing this work, cite the original article.

Original Publication:

Mathias Friman and Gustav Strandberg, Historical responsibility for climate change: science and the science-policy interface, 2014, Wiley Interdisciplinary Reviews: Climate Change, (5), 3, 297-316.

http://dx.doi.org/10.1002/wcc. 270

Copyright: Wiley: 12 months

http://eu.wiley.com/WileyCDA/

Postprint available at: Linköping University Electronic Press

http://urn.kb.se/resolve?urn=urn:nbn:se:liu:diva-104040 


\section{WIREs Climate Change}

\section{Article type: Advanced Review \\ Historical responsibility for climate change: science and the science-policy interface}

Mathias Friman* mathias.friman@liu.se

Centre for Climate Science and Policy Research, CSPR (Linköping University and the

Swedish Meteorological and Hydrological Institute), and Water and Environmental

Studies Unit, Department of Thematic Studies, Linköping University.

Gustav Strandberg

Centre for Climate Science and Policy Research, CSPR (Linköping University and the

Swedish Meteorological and Hydrological Institute), Rossby Centre, Swedish

Meteorological and Hydrological Institute, and Department of Meteorology, Stockholm

University.

\section{Abstract}

Since 1990, the academic literature on historical responsibility (HR) for climate change has grown considerably. Over these years, the approaches to defining this responsibility have varied considerably. This article demonstrates how this variation can be explained by combining various defining aspects of historical contribution and responsibility. Scientific knowledge that takes for granted choices among defining aspects will likely become a basis for distrust within science, among negotiators under the United Nations Framework Convention on Climate Change (UNFCCC), and elsewhere. On the other hand, for various reasons, not all choices can be explicated at all times. This article guides those who need to evaluate the assumptions underlying specific claims regarding HR. This article examines the full breadth of complexities involved in scientifically defining HR and discusses how these complexities have consequences for the science-policy interface concerning HR. To this end, this article maps, reviews, and classifies the academic literature on historical contributions to and responsibility for climate change into categories of defining aspects. One immediately policy-relevant conclusion emerges from this exercise: Coupled with negotiators' highly divergent understandings of historical responsibility, the sheer number of defining aspects makes it virtually impossible to offer scientific advice without creating distrust in certain parts of the policy circle. This conclusion suggests that scientific attempts to narrow the options for policymakers will have little chance of succeeding unless policymakers first negotiate a clearer framework for their establishment. 
Historical responsibility (HR) for climate change has become one of the thorniest issues in negotiations under the UN Framework Convention on Climate Change (UNFCCC). In its most abstract form, HR entails explicating the moral significance of history when distributing the responsibility to act on climate change. Although many agree that history does have moral significance, the political struggle over how this should influence the responsibility to act is marked by highly divergent understandings.

At the initial stage of negotiating the draft Convention, in early 1991, the degree to which countries had contributed to climate change was proposed as a measure of responsibility to act. Other proposals stressed that historical emissions and the responsibilities they might trigger should prompt developed countries to take the lead in dealing with climate change, although not necessarily in proportion to their contributions. ${ }^{1,2}$ At the time the UNFCCC was adopted in 1992, some argued that the division between Annex 1 and 2 countries, with differing specific commitments, and Parties not included in Annex 1 (non-Annex 1 Parties) corresponded to the acceptance and resulting operationalization of HR. However, in the process of specifying the UNFCCC in a protocol, the dispute between what we will term the 'conceptual' versus 'proportional' views of the moral significance of history was revived.

The conceptual view treats HR in a manner that avoids direct linkage between past emissions and present responsibilities. It typically looks at the present unequal distribution of capacity to act, and argues that the history of the creation of this distribution must be evaluated in moral terms. If the greater capacity to act in some parts of the world has been accumulated unfairly in the past, for example, through imperialism and colonialism, those possessing it have a moral responsibility to act. $^{3-7}$

The proportional view, on the other hand, defines responsibility in proportion to historical contribution. The segment of the literature espousing this view is more elaborated than that treating conceptual understandings. Unsurprisingly, the proportional view depends greatly on modeling historical contributions. Climate modeling is a thoroughly established field in climate science, which also explains the comparatively high level of detail in the literature on proportional HR. ${ }^{8-13}$

The various definitions of HR refer to vastly different quantifications of countries' relative shares of the global mitigation burden. In 2009, current US President Obama declared acceptance of the USA's $\mathrm{HR}$, operationalized in terms of taking the lead in emissions reductions. ${ }^{14}$ This translated into pledging US emissions reductions of approximately $3 \%$ in 2020, relative to 1990 levels. Calculations of the USA's contribution to climate change usually end up in the $20-25 \%$ range. ${ }^{11,15}$ Depending on how the global mitigation requirements are defined, a $25 \%$ relative responsibility for mitigation may indeed translate into high emissions reductions. The definition of HR proposed by Baer et al., ${ }^{15}$ weighted by population and capacity to act, has been quantified into emission allowances by Höhne and Moltmann, ${ }^{10}$ amounting to approximately $61 \%$ emissions reductions (relative to 1990 levels) by 2020 for the USA. Both examples refer to HR, with the wide range of prescribed emissions reductions having to do with how $\mathrm{HR}$ is defined.

\section{Purpose and organization}

Although several partial reviews of the literature are available, ${ }^{3,8,16-19}$ a broad, comprehensive review is missing; this article seeks to fill this gap. By intentionally keeping the scope broad, the 
review dissects the core assumptions underlying very different definitions of $\mathrm{HR}$, ranging from strictly proportional to strictly conceptual versions. Our aim is to illuminate the full breadth of the complexities involved in scientifically defining HR and to discuss how these complexities have consequences for the science-policy interface concerning HR.

We start by outlining the literature, resulting in a list of defining aspects relevant to constructing different versions/models of HR. However, this should not be seen as constituting a recipe for a 'complete' and 'correct' version of HR. If for no other reason, the inconsistency between the definitions of the various aspects makes an all-embracing approach to HR impossible. Instead, this review serves as an overview for researchers and a guide, particularly in policy circles, to understanding the lack of consistency between quantifications of HR for climate change. When concluding this article, we will reiterate what the findings of our review imply for international climate negotiations concerning HR. Given all the choices on the menu when it comes to defining $H R$, we introduce the history of science-policy interactions regarding HR in the UNFCCC, emphasizing that $H R$ is still a vital agenda item. While HR will not disappear from the agenda in the foreseeable future, the vast differences between scientific definitions of HR, the different traditions of framing climate change in developed and developing countries, and the characteristics of UNFCCC negotiating practice makes it virtually impossible to offer objective, scientific advice to policymakers on the best way to define HR. We conclude that HR cannot be defined objectively. On the contrary, it is inherently connected to inevitable political choice, no matter whether cloaked in traditional political garb or regarded as a concern for objective science.

\section{SCOPE OF REVIEW}

This review focuses on the literature treating relative HR to mitigate climate change. However, this review is also relevant to the growing academic literature on HR to finance adaptation or the literature defining carbon or climate debts. ${ }^{18,20,21}$ However, it should be noted that the climate debt literature focuses on responsibility to compensate for unequal access to the atmosphere, caused by disparities in countries' historical emissions.

Within this focus, we searched for relevant titles and abstracts in the SciVerse Scopus bibliographic database using the following keywords:

- Past/historic(al) AND responsibility/emission/contribution AND climate

The reference lists of articles retrieved were used to identify additional white and grey literature not covered by Scopus.

The reviewed literature covers a range of traditions, such as modeling, philosophy, political theory, economics, and environmental history. We choose to exclude the issue of choosing among data sources (e.g., concerning present vs. historical data on emissions/removals, populations, and income) other than at a very general level. We appreciate the importance of such choices, yet we believe that their complexities merit a review by themselves. We also adopt a common point of departure from the literature, namely, that states are the primary duty-bearers. However, if HR is defined using other duty-bearers, the exercise usually becomes more complex. For example, Caney,

${ }^{4}$ suggests that some responsibility may be assigned to supra-state institutions and that states 
cannot be fully responsible for their citizens' lack of action. This suggests that individuals themselves could be the primary duty-bearers, though how this would be possible in practice remains unresolved..$^{22}$ We acknowledge this debate yet align our point of departure with the Vienna Convention on the Law of Treaties that assumes that states are collective entities whose identities (and thus responsibilities) link past, present, and future citizens. ${ }^{3-5,18,23}$

Furthermore, we discuss choices solely in qualitative terms. We do not attempt to say which of the defining aspects affects quantifications the most. It is indeed difficult given that the choices are so interconnected and interdependent. One choice may be relatively important in one definition but relatively unimportant in another. Attempts to rate the relative importance of various defining aspects of HR have been made by, for example, den Elzen and Schaeffer ${ }^{9}$ and Höhne. ${ }^{17}$

\section{Categorization}

In pursuing the first part of our aim, i.e., to illuminate the full breadth of complexities involved in scientifically defining HR, we search the literature for the concept's 'atoms', i.e., the small building blocks used when researchers formulate more complex definitions of HR. Definitions of HR, more or less complex compounds, almost always obscure several of the choices made by researchers when using one building block and not another to define the specific characteristics of HR. We want to provide a record that resembles a periodic table (Table 1) listing the elements of HR. The motivation for creating this table is, on the one hand, to provide researchers and policymakers with an improved understanding of the choices made in various limited discussions and definitions of HR, and thus to illuminate the inherent complexity of and inconsistencies between various definitions. On the other hand, we want to base our conclusion that HR cannot be objectively defined on a thorough reading of the literature. This conclusion has profound implications for science's ability to help policymakers reduce options and select appropriate routes for politics. After discussing the literature, we would like to return to some of the consequences for the science-policy interface regarding $H R$.

In endeavoring to dissect the core scientific assumptions, we divide the HR literature into two orientations with fundamental and rather incommensurable points of departure: the proportional and conceptual views. We start by discussing the former of these.

\section{DEFINING ASPECTS OF PROPORTIONAL HISTORICAL RESPONSIBILITY}

Most of the defining aspects are found in the literature treating modeling that understands HR as proportional to contribution. Many of the uncertainties and complexities of today's attempts to condense the climate system into models are shared no matter whether the model is trying to forecast changes under certain scenarios or attributing more recent changes to specific past emissions. This section of the article, however, is confined to aspects of climate system modeling and change that are specifically addressed in the literature on historical contribution and responsibility, signaling that these aspects are of particular interest to the community working on this issue.

\section{Representations of the climate system and change}

The reviewed literature uniformly understands the climate system, in simplified terms, as a causeeffect chain (Figure 1). ${ }^{24}$ Changes in emissions affect, in stepwise fashion, greenhouse gas (GHG) 
concentrations, radiative forcing, temperature (absolute and rate of change), other climate change indicators (e.g., sea-level rise, precipitation, extreme weather events, winds, and soil moisture), impact (e.g., on society and ecosystems), and finally damage cost. ${ }^{12,17,24-26}$

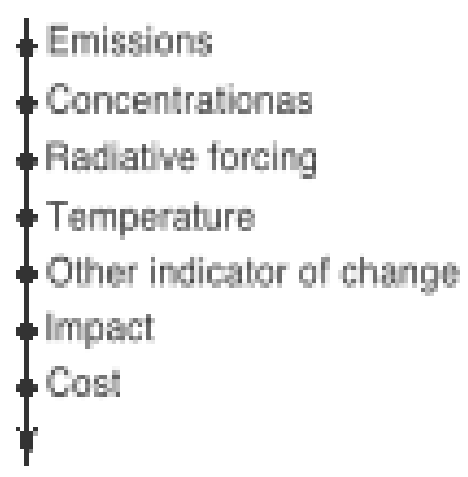

FIGURE 1 | Schematic of how the climate system is represented in the literature on proportional historical responsibility: as a cause-effect chain extending from emissions to impacts and costs. Policy relevance is seen, in the reviewed literature, as increasing further down the chain.

As a first choice in relation to proportional definitions of HR, the literature discusses complexity versus understandability: distributing responsibility based on causal relationships between emissions and climate change could either be as complex as the present understanding of the system allows or, as Höhne ${ }^{17}$ puts it, 'could accept the inherent difficulties of calculating contributions to climate change' (p. 66) and be pragmatically simple in order to be more understandable to end users. The better direction is far from obvious. ${ }^{19,25}$ At this stage, it is already obvious that no one can be in a position to objectively define the better version of historical responsibility.

How to understand model results along the simplicity-complexity continuum depends on choices between a great many factors. We discuss these choices under three categories: 1) model treatment of climate system nonlinearities, 2) choice of climate change indicators, and 3) how contribution to climate change is attributed to countries.

\section{Linearity/nonlinearity}

Climate scientists of course know that the climate system is nonlinear. Nonlinearity between emissions and concentrations relates, importantly, to the oceanic and terrestrial uptake of carbon. The ratio of carbon that remains in the atmosphere increases with increased concentrations of carbon dioxide $\left(\mathrm{CO}_{2}\right)$. This is referred to as the oceanic buffer factor and the $\mathrm{CO}_{2}$ fertilization effect. ${ }^{12}$ Atmospheric chemistry also affects the influence of emissions on concentrations. The turnover time of methane, for example, depends on the presence of a number of other gases, compounds, and ions, the concentrations of which may differ from time to time. ${ }^{19}$ These nonlinear dynamics are often, for the sake of simplicity, neglected in modeling historical contributions. ${ }^{17}$ In linear representations of the climate system, the effects of emissions are independent of the time of their release.

Nonlinearity in moving from concentrations to radiative forcing relates to saturation in absorption bands. Simply stated, the efficiency with which a GHG absorbs radiation decreases with increased 
concentration. Late emissions therefore have less effect, with some variation for different GHGs. ${ }^{12,16 \text {, }}$

${ }^{17}$ Some gases' ability to absorb infrared radiation also occurs in overlapping frequency bands, meaning that these gases saturate each other's capacity to recirculate heat. ${ }^{19}$ Most estimates of contribution to climate change try to represent this nonlinearity in the models used (see den Elzen and Schaeffer ${ }^{27}$ for an exception). Choosing to do so has the opposite effect to including oceanic and terrestrial carbon uptake. Instead of giving less weight to early emissions, nonlinearity between radiative forcing and concentrations of $\mathrm{CO}_{2}$ gives more weight to early emissions.

Giving objective policy advice is further challenged by the fact that historical contributions to climate change are not easily translated into historical responsibilities. For example, in a nonlinear representation, identical emissions pulses in, say, 1800 and 2000 have different effects on concentrations. This is because early emissions are released into an atmosphere with lower total concentrations. On the other hand, if it were not for the earlier emissions, the later emissions would have a relatively greater effect on concentrations. The different effects can be explained by the logarithmic nature of terrestrial fertilization and by the saturated buffering capacity of increasingly acidified oceans due to increased carbon concentrations. The answer as to whether or not early emissions ought to be 'blamed' for the increased effect of late emissions on $\mathrm{CO}_{2}$ concentrations is not straightforward. A similar question can be raised in relation to nonlinearity in moving from concentrations to radiative forcing. ${ }^{26}$

Since these alternative ways of representing the climate system influence the definition of proportional HR, Höhne ${ }^{17}$ notes that a 'decision to use a complex system with nonlinearities and feedbacks or to use a simplified linear system is therefore not only a technical, but also a political question, which should be taken with care' (p. 62).

\section{Indicators}

Another decision that must be made carefully is the choice of indicator for measuring contributions to climate change. Using different indicators of change shifts the relative responsibilities. ${ }^{8,17}$ The indicators are found at various positions along the cause-effect chain (Figure 1). Our exemplification of how the selection of different indicators affects assessments of HR starts at the upper end of the cause-effect chain and gradually moves towards the lower, which this literature regards as the more policy-relevant end of the chain. Although we acknowledge several important and highly policy-relevant mitigation issues that come before emissions in Figure 1, the literature on proportional HR starts from what has been emitted rather than emissions that have been avoided.

Starting with an example at the upper end of the chain, it has been proposed that cumulative emissions could be used as an indicator of climate change. ${ }^{28,29}$ This indicator stacks emissions; as such, it accounts for neither the effects of emissions nor for nonlinearities in the climate system. Moving down the cause-effect chain, increase in concentrations ${ }^{9,28,30}$ has been proposed as a measure for determining proportional responsibility that, contrary to cumulative emissions, accounts for uptake of carbon (either linearly or nonlinearly). In comparison with cumulative emissions, increase in concentrations gives less weight to early emissions, more so under nonlinear than linear assumptions.

Using increase in concentrations as an indicator is not suitable when choosing to compare different gases in a single responsibility measure, since it does not make sense to sum the concentrations of 
different gases. ${ }^{24}$ As such, this version of HR would have to set different targets for different gases, or be based on a single gas. ${ }^{31}$ Höhne ${ }^{17}$ suggests that the change in radiative forcing in a given year could be used as an indicator that enables the comparison of different GHGs in a single measure. This indicator accounts for both uptake and saturation (linearly or nonlinearly). ${ }^{9}$ In any case, it would not take future (delayed) effects into consideration; compared with indicators that would, it therefore normally downplays the importance of more recent emissions.

One proposed way of accounting for the future effects of emissions is to use global warming potentials (GWPs). GWPs relate a GHG's radiative forcing over a certain time period, usually 100 years, to the radiative forcing of $\mathrm{CO}_{2}$ over the same period. As such, it provides a measure by which various GHGs can be made comparable. Using cumulative GWP-weighted emissions as an indicator of climate change multiplies cumulative emissions until a given year by GWPs. ${ }^{8,17}$

Since this indicator is based on cumulative emissions, and since GWPs assume a linear relationship between emissions and concentrations when calculating the future effect, it would not account for carbon uptake or saturation. Furthermore, as noted by Shine et al., ${ }^{24}$ the selected timespan of the GWP shifts responsibilities: the importance of GHGs with shorter atmospheric lifetimes, such as methane, would increase with shorter timespans and vice versa for longer-lived GHGs. Using cumulative GWP-weighted emissions would therefore also depend on the chosen mix of GHGs and the time horizon of the GWPs.

Much more could be said on this topic. A set of quite different indicators has also been proposed, including change in radiative forcing, ${ }^{9,17}$ integrated temperature increase, ${ }^{17,32}$ average global surface air temperature increase, ${ }^{9,17,26,32-36}$ rate of temperature increase, ${ }^{9}$ sea-level rise, ${ }^{8,9,37}$ and impact on society, ${ }^{38,39}$ all of which have their peculiarities. We will not describe all these indicators in detail; the important messages are that they all shift relative responsibilities back and forth, and that, fundamentally, there is no way of objectively determining which one, if any, is the best measure for assigning proportional historical responsibilities to states. The literature emphasizes that damage is one of the more policy-relevant indicators available, but also one with a huge range of uncertainty. On the other side of the spectrum are the more robust measures. The literature generally agrees that getting closer to climate damage makes responsibility calculations more precise. However, this runs into all sorts of practical problems, so focusing on entities earlier in the cause-effect chain is often seen as more practicable. Again, the choice between policy relevance and robustness is not straightforward.

\section{Attribution methods}

Under linear conditions, individual contributions normally sum to the global value, so no method separate from the model itself should be needed to determine individual contributions. However, if nonlinearities are introduced into the models, the individual contributions normally do not sum to the global reference case. Such deficits are treated using an attribution method. Different attribution methods provide different relative responsibilities, again highlighting the fact that modeling contribution to change to determine proportional historical responsibilities involves decisions whose effects are not always easily understandable for end-users of the calculations. 
The most commonly cited attribution methods are the marginal, ${ }^{12,17,19,32}$ proportional, $12,17,26$ residual, ${ }^{12,17}$ differential, ${ }^{12,}{ }^{40}$ time-sliced, ${ }^{12}$ global turnover, ${ }^{9,12,41}$ and cumulative stock ${ }^{12,35,42}$ methods.

Let us consider two attribution methods, selected as examples because they represent the two most common approaches used in the literature: the marginal and the residual. The marginal attribution method equalizes the effects of all previous units of emissions/concentrations/radiative forcing to that of the last additional unit (i.e., latest, on the margin). ${ }^{26}$ If applied in the step from emissions to concentrations, the relative contributions of early emitters increase. This is, as explained above, because late emissions have a greater influence on concentration than do early ones. When the effect of early emissions is considered the same as that of the last additional unit, the earlier emissions are counted as if they have the same greater effect as do the latest. In contrast, if applied in the step from concentrations to radiative forcing, as is usual, it reduces the relative contributions of early emitters since they would benefit from the same (higher) amount of saturation as would late emissions. ${ }^{12,17,19,32}$

The residual, or all-but-one, method calculates the effect of all emissions on a chosen indicator. It then subtracts the emissions from an individual contributor, and calculates the effect of the remaining emissions on the indicator. The difference between the two cases is considered the relative contribution to climate change from the individual contributor. ${ }^{17}$ The method has been described as benefiting from simplicity. However, when applied to a model that includes nonlinearities, the effect of emissions from, for example, a region comprising several countries does not equal the sum of the effects of its individual contributing countries. If used to derive concentrations from emissions (nonlinearly), aggregation into regions results in a lower contribution from the total region than from each country taken separately (e.g., the EU versus the sum of its member states). If used to derive radiative forcing from concentrations, the opposite occurs (favoring the disaggregation of regions). Small emitters are favored in the former case and large emitters in the latter. ${ }^{12}$

\section{Calculation entities}

On top of the various ways of representing the climate system in climate models, the literature introduces a number of necessary calculation entities to establish the framework for the model. The most obvious of these entities relate to various aspects of the chosen timeframe and gases. Sometimes, geographic factors are also discussed. When establishing proportional historical responsibilities, choices between these calculation entities cannot be avoided. Yet again, decisions as to which entities to choose and thus which to exclude are by no means, as we hope to demonstrate, self-evident.

\section{Gases and aerosols, sources and sinks}

First, the choice of which GHGs to include when calculating contributions to an indicator shifts the relative responsibilities of countries, sometimes rather dramatically. ${ }^{8,19}$ Two approaches are more common: the first attaches responsibilities to all GHGs regulated under the UNFCCC, whereas the second starts with GHGs available in historical datasets. It should be noted that historical emissions of GHGs that are not regulated under the UNFCCC, such as chlorofluorocarbons (CFCs), are rarely 
cited when defining proportional HR, yet this alternative way of defining HR has also been suggested. ${ }^{18}$

The choice of GHGs generally also relates to the chosen timeframe, since data on many gases are poor or nonexistent over longer timeframes. Generally, the literature tends to focus on $\mathrm{CO}_{2}$, for which the data are most numerous, which generally increases the relative responsibility of developed countries compared with use of a broader range of GHGs.

Another example in this category relates to aerosols. If included, the effects of various aerosols are almost always accounted for on a global level. ${ }^{9}$ However, Andronova and Schlesinger ${ }^{35,42}$ have attempted to attribute the cooling effects of sulfate aerosols to emissions over regions when quantifying the same regions' contributions to temperature change. The literature therefore identifies available options among the various factors involved in defining HR in this area as well. How this affects relative responsibilities is very case dependent.

Not only which gases to include but also their various sources have to be chosen. Whether and how to quantify historical emissions from, for example, land-use change and forestry (LUCF) is debated. In any case, doing so dramatically increases the uncertainty of calculations, which has prompted many to avoid entering emissions from LUCF into the calculations. ${ }^{13,43,44}$ If it is done, MartinezAlier ${ }^{45}$ also argues that sinks ought to be considered when assigning relative responsibilities. Sinks are indeed almost always included when modeling a global reference case. Yet, the point here is whether to include sinks as emissions reductions connected to specific countries, for example, HR assigned to avoided deforestation or enhanced land use within or beyond state territory. Muylaert de Araujo et al. ${ }^{46}$ also conclude that both developed and highly populated countries have been the main emitters of nitrous oxide from manure management and methane from enteric fermentation related to domestic livestock. If this sector were included, it would generally raise relative responsibilities of these countries. In contrast, in existing evaluations accounting for sources and sinks in the forestry sector, the relative responsibilities of developing countries, in the aggregate, increase. ${ }^{8}$ These calculations increase complexity, and are often seen as more accurately trying to mirror actual climate dynamics; however, they also increase the uncertainties and decrease the comprehensibility, which tends to make the quantifications less useful in drafting policy regarding responsibility distribution.

\section{Datasets}

The most obvious of the needed input data relate to past emissions. However, if contribution to climate change is adjusted to, for example, capacity to act, population, or area of a country when determining HR, other data are needed too. On this topic, we merely want to point out that choosing between different datasets will affect relative responsibilities. Emissions data, however, have been more thoroughly discussed in the HR literature than have other types of data. Two important comments on this topic follow, in keeping with our general remarks.

First, there are several different datasets on past emissions, particularly for periods after 1950 . The most used datasets that contain emissions data for countries and/or regions and that cover a century or longer are EDGAR-HYDE, CDIAC-ORNL, and IIASA. Commenting on these databases, den Elzen et al. ${ }^{19}$ have noted that considerable uncertainty still exists even for the best-known emissions, i.e., $\mathrm{CO}_{2}$ from fossil fuel. As long as the uncertainties apply equally to all regions/countries, they have 
little bearing on the assigning of relative responsibilities. However, the kinds of uncertainties that relate to datasets are usually region or country specific. For example, even if the estimates of emissions from fossil fuel burning are based on the amount of, for example, coal, oil, and gas being burnt, den Elzen et al. ${ }^{19}$ note that the change in 'energy content per unit of mass, e.g., coal, is not well known for all countries' (p. 31), which results in different uncertainties for different regions/countries. Nevertheless, the databases generally indicate only slight variation concerning fossil fuel-related $\mathrm{CO}_{2}$ emissions, with more variation in data for times before $1950 .^{9,47}$

Data on $\mathrm{CO}_{2}$ emissions from land use and LUCF are considerably more uncertain, and such data vary substantially between databases. If land use and/or LUCF are included, the importance of the choice of database increases, especially if nitrous oxides and methane from these sources are included as well. Therefore, the choice of, composition, and sources of gases to which to assign responsibilities have a bearing on the importance of choosing one or another database (or combination of databases) for calculations of relative contribution to climate change.

Second, if the chosen timeframe gives rise to more general gaps in emissions data, these gaps must be treated in one way or another, usually by extrapolation. However, those who are evaluating various definitions of proportional HR might want to pay attention to these limitations of the datasets.

\section{Timeframe: start date}

Another choice that substantially alters relative historical responsibilities is setting a start date for 'history'. ${ }^{8,17,48}$ Some simply choose a start date based on data availability, as discussed above. ${ }^{30}$ However, many calculations start at the beginning of industrialization in order to assign responsibility for anthropogenic emissions in general. ${ }^{37,49}$ There is no set year when industrialization is agreed to have started, but it is often argued that concentrations of $\mathrm{CO}_{2}$ have risen steadily due to fossil fuel burning since $1751 .{ }^{47}$ Normally, any year between 1750 and 1840 is used. Under many circumstances, however, a 1750 start date, compared with 1840, would increase the contributions of Western Europe and Asia. ${ }^{9}$ However, the consequences of one or another start date differ depending on the attribution methods and indicators used.

The most common arguments for choosing a later start date relate to what Müller, Höhne, and Ellerman ${ }^{11}$ term the epistemic constraint. This limits responsibility to emissions that governments arguably knew, or should have known, would cause harm. ${ }^{6,28,50-52}$ Those favoring an epistemic constraint often use 1990 as a start date, concurrent with the release of the IPCC First Assessment Report, sanctioned by its member states (however, arguably, a fairly limited number of members at that time). In conjunction with this, it is noted that this was also when intergovernmental negotiations leading to the UNFCCC started. Thus, by 1990, states could hardly have been unaware of the potential negative effects of GHG emissions. Others have proposed using the tabling of the Second Assessment Report, in 1995, since it marks the first time the IPCC unanimously agreed that anthropogenic emissions affect the climate..$^{53}$ Schüssler, ${ }^{52}$ on the other hand, argues that the effects of GHGs were already widely known by 1950 , while Neumayer ${ }^{18}$ claims that the mid 1980 s witnessed the emergence of widespread knowledge of the harmful effects of GHGs. Finally, the epistemic constraint is evoked in juridical terms as well, to justify a start date of 1994, when the UNFCCC entered into force, or in 1997, when the Kyoto Protocol was adopted..$^{52}$ 
In this connection, some also differentiate between liability and responsibility. ${ }^{54,52,55} \mathrm{~A}$ state could be morally responsible for acting without being legally liable. With this contextual argument in mind, several commentators ${ }^{18,56}$ have responded that the epistemic constraint is morally unacceptable, since those that have benefitted the most from emissions (usually agreed to be the richer countries of the world) ought also to accept the costs attached to these benefits. Others reply that benefits arising from past emissions, for example, the development of technology or medicine, are seldom completely limited to a given state's territory. ${ }^{57}$ Caney $^{3}$ has even claimed that a version of HR that focuses on benefits shifts proportionality away from the contribution of emissions to climate change towards the contribution of emissions to benefits.

Finally, some argue that responsibilities for historical emissions cannot be claimed from dead people. ${ }^{52,57}$ On this basis, Schüssler ${ }^{52}$ argues that 1950 provides a good starting point, since most people currently living were born after 1949. In moral philosophy, this point is also made with reference to the so-called non-identity problem ${ }^{5,53}$ : If climate change had not occurred, the world would be different and currently living people would not have been born. If this is accepted, they claim, current populations are not beneficiaries of historical emissions since, compared with a history with no emissions, they would not exist. Proponents of full responsibility typically argue that states ought to be seen as the primary duty-bearers, noting that states' identities span generations of their citizens. From that perspective, state responsibility does not naturally follow past generations of citizens into the grave. ${ }^{18,56}$

In many cases, these debates in their essence concern whether states, individuals, or other entities are seen as the relevant duty-bearers. In the context of choosing a timeframe for calculations, it is enough to be aware that these choices serve as rationales for choosing one or another start year for determining proportional HR. The debate is ultimately unresolved.

An earlier start date generally increases the responsibilities of developed countries. However, the relative contributions of former Soviet states tend to increase, together with those of developing countries, with later start dates (particularly after 1950).

\section{Timeframe: end and/or evaluation date}

Choosing an end date is as necessary, and as problematic, as choosing a start date. ${ }^{8}$ After the end date, further emissions are no longer counted as contributing towards assigning responsibilities. Sometimes the evaluation date, i.e., the year in which the effects of the emissions up to the end date are evaluated, equals the end date. If so, the results will typically give more weight to earlier rather than more recent emissions, ${ }^{17}$ especially for indicators further down the cause-effect chain (Figure 1). For example, translating radiative forcing into temperature increase entails choosing how quickly a change in forcing affects temperature. Considerable uncertainties, for example, in how the ocean takes up heat, make the range of possible response times large. ${ }^{9}$ Assuming a quick response time generally gives more weight to late emissions than does assuming a slow response time. If, for example, sea-level rise is used as an indicator, the response time increases even further.

Furthermore, the maximum effect of different GHGs on, for example, temperature occurs at different timescales. This means that choosing the evaluation date can be even more complicated if, for example, average global surface temperature is used as an indicator. Generally, the further away the evaluation date is set from the end date, the more weight is given to later emissions. ${ }^{8}$ To account 
for how the contribution of past emissions to several indicators depends on the possible future atmospheric composition, the effects of historical emissions are sometimes evaluated under different emissions scenarios. ${ }^{9,} 58$ Even if constrained to IPCC SRES scenarios, several choices still need to be made, for example, between scenario family and marker scenario.

To complicate things even further, some choose a future end date for emissions even though the emissions from the present up to the end date are unknown. ${ }^{29,41,50}$

Let us again be clear that none of these choices is more correct, better, or more useful than others for determining proportional historical responsibilities. Different arguments are used to justify the different calculations in a debate that is ultimately anchored in values rather than facts.

\section{Geography}

The fact that borders have changed throughout history complicates assigning proportional HR to states. ${ }^{3,57}$ Not only does this pose a challenge for the obvious reasons (i.e., responsibility for nonexistent states or recently created states), but this defining aspect is further complicated if the definition of proportional HR involves attribution methods that are not additive in the sense that the contribution of one area is not the same as if it were disaggregated into more than one region or aggregated into a larger region (cf. the residual attribution method discussed above).

Caney $^{3}$ argues that new states have no responsibility for the emissions of previous states that formerly had authority over the same territory. However, the usual way to address changing borders is to ascribe responsibility for historical emissions over a state's present territories, no matter whether the current authority over the territory has a new or old name, noting that the borders of the largest emitters have remained relatively stable. ${ }^{18,55}$ Still, when there is a lack of data in the chosen timeframe, this approach requires that the gaps be filled. As noted by Müller, Höhne, and Ellerman, ${ }^{59}$ some data can be adjusted to accommodate changing geographical borders. If not, they propose backward extrapolation. Neumaye ${ }^{18}$ proposes that gaps may be filled using population share or GNP share as a proxy for historical emissions. How this shifts responsibilities is very case dependent: new African states, for example, typically have low responsibilities in any case, whereas former Soviet states would see their responsibility increase greatly if Soviet era emissions were also accounted for.

In this regard, it is also noted that some territories are not subject to state authority, so accounting for matters such as emissions from international shipping and aviation in these territories would possibly have to be introduced into the models based on some other logic. ${ }^{11}$

\section{Adjustment factors}

Several aspects have been raised as possible factors to consider when adjusting proportional HR. Proportionality can be defined without these but, if included, their influence could be large. These options are discussed in the following.

\section{Populations}

The idea of using population-adjusted contributions arises from a desire to 'remove the differences between countries' relative historical contributions due to their population sizes' (Rive and 
Fuglestvedt, ${ }^{60}$ p. 142). Although very few have suggested that proportional HR should be population adjusted, those who have elaborated on this possibility have done so in many different ways that are more or less complicated depending on the choices made between the defining aspects discussed above. ${ }^{30,49,60-62}$

In summary, adjusting indicators by population levels will affect proportional responsibility by leading to several choices among defining aspects. These relate to sometimes subtle considerations of, for example: the use of different sources of population data, historical (dynamic) population levels versus a static (present or otherwise) population level, and how the weighting corresponds to the chosen indicator(s), timeframe, and population growth scenarios.

To exemplify how these choices can affect proportional HR, consider two countries with equal contributions to climate change and very similar aggregated historical population levels. Country $\mathrm{A}$ has seen a recent rapid decline in population by migration to country $B$, which thus has seen a recent rapid increase. Using a static population level (near present) would increase the responsibility of country A relative to that of B. If historic population levels were accounted for, these countries' responsibilities would be quite similar, at least if the timeframe was long enough to marginalize the more recent migration trend. Though this example is schematized, it nevertheless clarifies one of the more immediate differences between the approaches to using historical versus present population levels. Combinations are of course possible, and have sometimes been proposed. ${ }^{18}$

\section{Trade (production and consumption)}

Some have suggested that proportional HR should account for exports and imports. ${ }^{11,50,59} \mathrm{~A}$ sole focus on emissions over territory, some argue, overlooks a joint responsibility for emissions divided between producers and consumers when these fall under different state authorities. ${ }^{50}$ If this approach is chosen, choices also have to be made between different world trade datasets. The concept of joint contribution adds another possibility to the list of choices to be made: states can share responsibility for emissions relating to international trade. ${ }^{11}$ In such cases, the sharing ratio also has to be chosen. The joint contribution literature clearly resembles the literature on emissions embodied in trade and consumption-based accounting, which is likely to inform future discussions of proportional HR. ${ }^{63-65}$

Adjusting proportional HR so as to factor in states producing goods for consumption in other states has a greater effect if the start date for determining contribution is relatively recent (say, 1990 rather than 1750).

\section{Development needs, capacity, and costs; area; political systems and migration}

A whole set of other adjustment factors has been proposed as well. We will briefly discuss these for the sake of comprehensiveness and transparency in completing the 'periodic table' (Table 1) of elements discussed in the literature on defining HR, and to bolster our argument that HR cannot in any way be objectively defined.

Some argue that emissions inevitable for subsistence or survival purposes should not incur any responsibilities (typically 2 tons of $\mathrm{CO}_{2 \text { eq }}$ per person and year). ${ }^{11,66,67}$ Others ${ }^{8,15}$ propose establishing a participation threshold. Once a country has reached a sufficient development level (e.g., expressed in emissions per capita above the global mean and sufficient income per capita), participation in a 
mitigation regime is required. These approaches differentiate a global responsibility based on historical contributions while taking the need for development into account.

These proposals imply that a country with a great responsibility might not have the capacity to act. The literature also makes the opposite argument: responsibility could be low but capacity high. ${ }^{22}$ Some argue that proportional HR is pragmatically complicated because of these aspects, as those with the most responsibility might simply not be in a position to afford the associated costs. ${ }^{68}$

It has also been proposed that historical emissions from deforestation should reasonably be expressed in terms of the area of the country, as emissions per hectare. ${ }^{13}$ Still others ${ }^{3}$ ask whether it is morally justifiable for an individual living under a dictatorship to have to pay for the wrongdoing of the state. Another example is that of immigrants, who have moved into a given state's territory but whose ancestors lived elsewhere. ${ }^{69}$ How to take account of these factors when adjusting proportional HR, however, is unclear. What many of these arguments imply is instead that holding a state responsible for its causal contribution to climate change is morally complicated and that, if history has any moral significance when distributing responsibilities for climate change, it should be done in a more conceptual than proportional manner.

\section{DEFINING ASPECTS OF CONCEPTUAL HISTORICAL RESPONSIBILITY}

As mentioned in the introduction, the conceptual view is less elaborated on in the literature. This view is based on either an understanding of rich states' emissions pathways in very broad (i.e., unquantified) terms, or on the historically unfair cumulative capacity to act, as a reason for developed countries' taking the lead in responding to climate change. Much of this literature is devoted to the complexities of proportional HR, mainly to argue that such approaches are inappropriate. However, some attempts have also been made to develop alternatives. These can broadly be categorized as conceptual versions focusing either on capacity or on trying to find pragmatic solutions.

\section{Capacity, wellbeing, and benefits}

Caney $^{3}$ argues that injustice during imperial and colonial history justifies assigning HR for climate change to those with the capacity to act. However, it must be noted that this in turn raises the question of whether the HR should stand in proportion to capacity. Some authors propose that proportional HR could be captured by a simpler capacity indicator since the correlation between the two is, they argue, quite high. ${ }^{70}$

A further example of a focus on capacity, in relation to attaching significance to past emissions, is provided by Meyer. ${ }^{6}$ Although Meyer in principle accepts a causal relationship between past emissions and responsibility, he rejects proportionality. Instead, he emphasizes the causal relationship between past emissions and current wellbeing to argue that those above a certain level of wellbeing have a greater responsibility to act. Gosseries, ${ }^{53}$ in a somewhat similar argument, concludes that compensation can be demanded from countries that have benefitted from past emissions at the cost of other (contemporaneous) countries. Jagers and Duus-Otterström ${ }^{22}$ remind us, however, that 'defining the most advantaged is never going to be easy' (p. 17).

In all of these cases, we may indeed be left having to establish a responsibility proportional to an indicator such as capacity, wellbeing, or benefits. Doing so might be, but is not necessarily, easier than assigning responsibility in proportion to contribution. 


\section{Pragmatism}

Some authors maintain that equity stands in opposition to a pragmatic solution to climate change, and normally oppose concepts such as HR to begin with. ${ }^{71}$ Many proponents of HR in the UNFCCC negotiations, on the other hand, emphasize that it is a precondition for an effective regime. ${ }^{72}$ However, there are two other versions, sometimes referred to as pragmatic, of how to define HR. First, Schüssler ${ }^{52}$ has argued that even though one may reject the notion of a moral obligation, it may still be morally legitimate to accept some form of HR (p. 262). He argues that, because of problems identifying duty-bearers (from certain perspectives of moral philosophy or from the perspective of international law), it is difficult to identify an obligation to take HR. However, if the subject matter moves from the domain of moral philosophy and law to practical politics, it is indeed possible that, for example, national parliaments may agree that such obligations should exist.

Second, HR is sometimes seen as accounted for by developed countries' taking the lead in tackling climate change. Rajamani ${ }^{73}$ argues that the division into Annex 1 and non-Annex 1 countries under the UNFCCC, with specific responsibilities assigned to each group, operationalizes HR under the Convention. From a conceptual perspective, this may indeed be the case, but it is certainly not in line with defining $H R$ as standing in proportion to contribution (or capacity). If this division is to be seen as determining how HR should be understood in international climate diplomacy, this understanding needs to be specified under the UNFCCC. Currently, it is not. Proponents of both this specific conceptual version, and of various proportional versions, are struggling to gain the preferential right to define the concept. This leads us to discuss the political implications of the various definitions of HR available in the literature, and to cite examples of some of the science-policy interactions that have occurred at the international level over the last 15 years. However, these conclusions will be clearer if we first summarize the aspects to choose from in the literature when defining HR for climate change.

\section{SUMMARY OF DEFINING ASPECTS}

We hope that it is by now clear that HR cannot be defined on the basis of objective reasoning. Any definition of HR involves choosing between a great many options and directions. Although we acknowledge that evaluating the different choices in a 'Country A vs. Country B' approach would be, in theory, very helpful, precisely because of the comprehensiveness of the HR literature, a proper 'Country A vs. Country B' approach is suitable in only a very limited set of cases; otherwise, it would increase the length of the review beyond any reasonable size. For most defining aspects, it is the 'cocktail effect' of the other choices made that will affect the outcome for 'Country A' vs. 'Country B.' In one cocktail (i.e., one combination of defining aspects), choosing a particular indicator of climate change can result in Country A having less responsibility than Country B. In another cocktail, the same choice of indicator could have the opposite effect on relative responsibilities. Reviews of HR have tended to focus narrowly on the influence of one or a set of aspects when applied in a certain model or set of models. Much as with chemicals, the effects of more than a limited number of aspects defining HR, taken together, are very difficult to predict and have largely been ignored. Our point is that, precisely because of such 'cocktail effects', debates over HR never have been, and never can be, completely resolved by objective science. The categories of aspects that constitute elements for building different versions of HR are compiled in Table 1. 
We propose categorizing the literature on HR for climate change into two broad orientations, proportional and conceptual, the sub-categories of the former having been developed in far greater detail. There are at least two reasons for this discrepancy. First, the proportional view is dependent on climate modeling. When adjusting simple climate models to determine a duty-bearer's contribution to climate change, the numerous possibilities discussed reflect the extensive literature on climate modeling. When translating contribution into responsibility, much of this literature also has to relate the discussion of historical contribution to the broader literature on responsibility for climate change. Second, the conceptual view is more engaged in arguing why the proportional view is, in various ways, problematic. Those preferring conceptual definitions of HR instead rely on establishing this view in opposition to proportional understandings. They then defer specifying the distribution of responsibilities to the literature on developing measures of the ability to act, or propose that international law advance action in developed countries before or above action in developing countries.

Definitions of HR, and their related defining aspects (i.e., building blocks), are already numerous. However, categorizing the literature also identifies many possible combinations of aspects used to arrive at definitions that have not yet been proposed. It also, we think, illuminates many possibilities for introducing even more categories of aspects and more alternatives into already established categories that could be considered when defining HR. If we connect these findings to the UNFCCC process, we see that the huge number of existing definitions, alternative compilations, and potential new definitions poses a major challenge for policymakers seeking to draft consensus outcomes in the UNFCCC process. 
TABLE 1 Summary of choices between aspects defining HR for climate change that have been discussed in the literature.

\begin{tabular}{|c|c|c|c|}
\hline $\begin{array}{l}\text { Choice between meta- } \\
\text { orientations in defining } \\
\text { historical responsibility }\end{array}$ & $\begin{array}{c}\text { Categories of choices specific } \\
\text { to the different meta- } \\
\text { orientations }\end{array}$ & Sub-categories & $\begin{array}{c}\text { Choices between specific } \\
\text { aspects in defining historical } \\
\text { responsibility }\end{array}$ \\
\hline \multirow{35}{*}{ Proportional } & \multirow{24}{*}{ Climate system } & \multirow{6}{*}{ Linearity/nonlinearity } & $\begin{array}{c}\text { Emissions } \rightarrow \text { concentrations: } \\
\text { oceanic uptake }\end{array}$ \\
\hline & & & $\begin{array}{c}\text { Emissions } \rightarrow \text { concentrations: } \\
\text { terrestrial uptake }\end{array}$ \\
\hline & & & $\begin{array}{c}\text { Concentrations } \rightarrow \text { radiative } \\
\text { forcing: saturation in } \\
\text { absorption }\end{array}$ \\
\hline & & & $\begin{array}{c}\text { Concentrations } \rightarrow \text { radiative } \\
\text { forcing: overlapping frequency } \\
\text { bands }\end{array}$ \\
\hline & & & $\begin{array}{c}\text { Radiative forcing } \rightarrow \\
\text { temperature }\end{array}$ \\
\hline & & & $\begin{array}{l}\text { Effects on GHGs of non-GHGs } \\
\text { and substances }\end{array}$ \\
\hline & & \multirow{11}{*}{ Indicators } & Cumulative emissions \\
\hline & & & Increased concentrations \\
\hline & & & Changed radiative forcing \\
\hline & & & $\begin{array}{l}\text { Cumulative GWP-weighted } \\
\text { emissions }\end{array}$ \\
\hline & & & Weighted concentrations \\
\hline & & & $\begin{array}{l}\text { Average global surface } \\
\text { temperature increase }\end{array}$ \\
\hline & & & $\begin{array}{l}\text { Integrated temperature } \\
\text { increase: } \\
\text { integrate past } \rightarrow \text { future }\end{array}$ \\
\hline & & & $\begin{array}{l}\text { Integrated temperature } \\
\text { increase: } \\
\text { integrate present } \rightarrow \text { future }\end{array}$ \\
\hline & & & Rate of temperature increase \\
\hline & & & Sea-level rise \\
\hline & & & Societal impact \\
\hline & & \multirow{7}{*}{ Attribution methods } & (Normalized) marginal \\
\hline & & & Proportional \\
\hline & & & Residual, all-but-one \\
\hline & & & (Normalized) differential \\
\hline & & & Time-sliced \\
\hline & & & Global turnover \\
\hline & & & Cumulative stock \\
\hline & \multirow{11}{*}{ Calculation entities } & \multirow{4}{*}{ Gases and aerosols } & $\begin{array}{c}\text { All GHGs regulated under the } \\
\text { UNFCCC }\end{array}$ \\
\hline & & & $\begin{array}{c}\text { GHGs available in historical } \\
\text { datasets }\end{array}$ \\
\hline & & & Include CFCs \\
\hline & & & Include sulfate aerosol \\
\hline & & \multirow{3}{*}{ Sources and sinks } & Land use and land-use change \\
\hline & & & Forestry \\
\hline & & & Domestic livestock \\
\hline & & Datasets & $\begin{array}{c}\text { Choices between using } \\
\text { different datasets }\end{array}$ \\
\hline & & \multirow[t]{3}{*}{ Timeframe: start date } & $\begin{array}{l}\text { All human-induced emissions } \\
\text { (typically, start of } \\
\text { industrialization) }\end{array}$ \\
\hline & & & Epistemic constraint \\
\hline & & & Non-identity \\
\hline
\end{tabular}




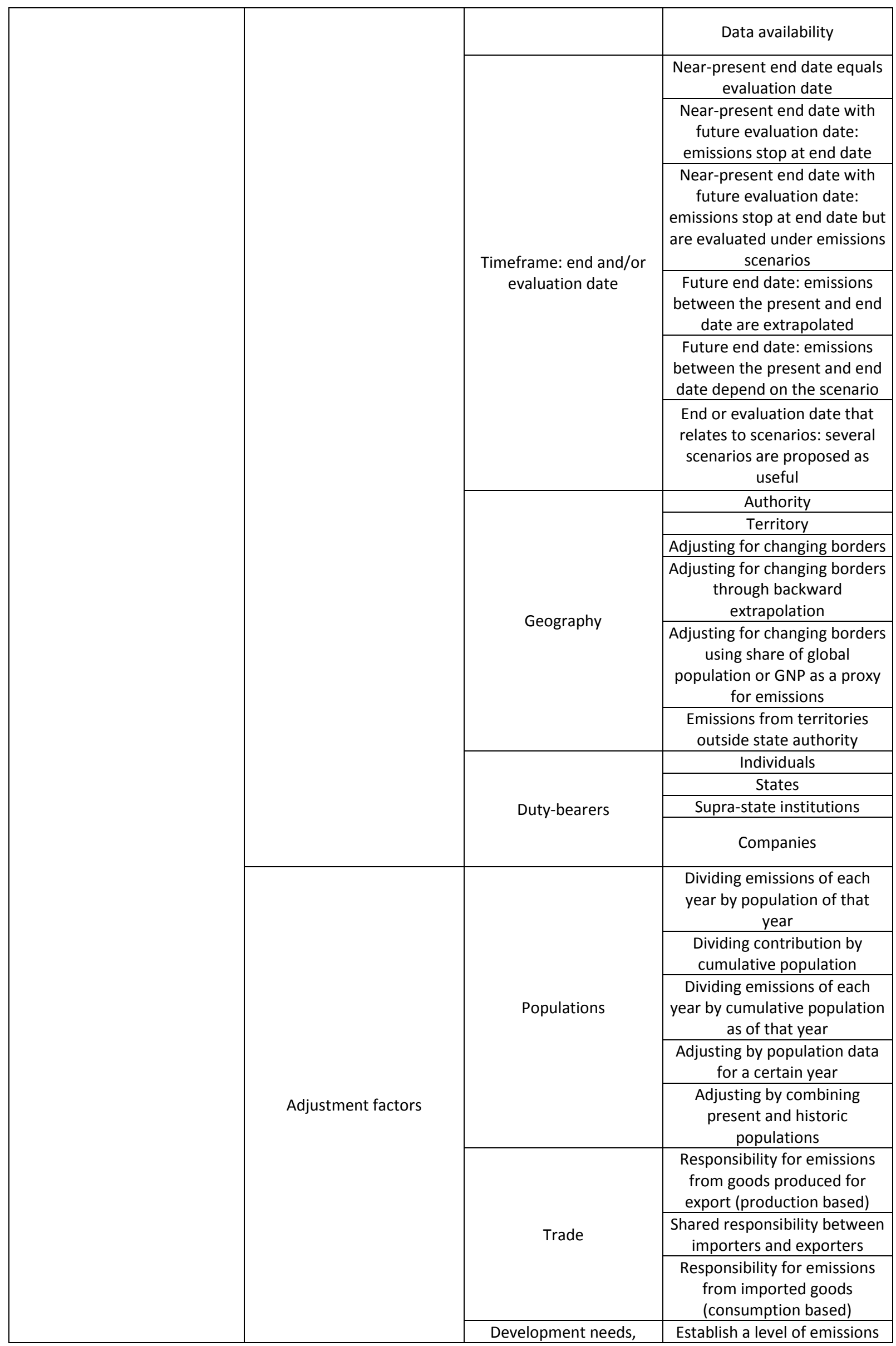




\begin{tabular}{|c|c|c|c|}
\hline & & \multirow[t]{3}{*}{ capacity, and costs } & $\begin{array}{c}\text { tied to survival or subsistence } \\
\text { for which no responsibility is } \\
\text { demanded: } 2 \text { tons of } \mathrm{CO}_{2 \text { eq }} \text { per } \\
\text { capita per year }\end{array}$ \\
\hline & & & $\begin{array}{c}\text { Development needs defined: } \\
\text { capacity above development } \\
\text { threshold determines the } \\
\text { share of HR that is not } \\
\text { connected to development } \\
\text { needs }\end{array}$ \\
\hline & & & $\begin{array}{l}\text { Responsibility for all emissions } \\
\text { is demanded once a certain } \\
\text { level of development is } \\
\text { reached }\end{array}$ \\
\hline & & Area & $\begin{array}{l}\text { Emissions from deforestation } \\
\text { adjusted by area of country }\end{array}$ \\
\hline & & \multirow{2}{*}{$\begin{array}{c}\text { Political systems and } \\
\text { migration }\end{array}$} & Democratic constraint \\
\hline & & & Migration adjustments \\
\hline \multirow{5}{*}{ Conceptual } & \multirow{3}{*}{$\begin{array}{l}\text { Capacity, wellbeing, and } \\
\text { benefits }\end{array}$} & $\begin{array}{l}\text { Unfair accumulation of } \\
\text { capacity }\end{array}$ & $\begin{array}{c}\text { Capacity as indicator of } \\
\text { historical responsibility: } \\
\text { GDP/capita }\end{array}$ \\
\hline & & $\begin{array}{l}\text { Level of wellbeing } \\
\text { embodies past emissions }\end{array}$ & $\begin{array}{l}\text { Indicators of wellbeing used as } \\
\text { proxies for historical } \\
\text { contributions }\end{array}$ \\
\hline & & $\begin{array}{l}\text { Benefits from past } \\
\text { emissions }\end{array}$ & $\begin{array}{l}\text { Beneficiaries to compensate } \\
\text { for costs of climate change } \\
\text { borne by other countries }\end{array}$ \\
\hline & & $\begin{array}{l}\text { Differentiation in } \\
\text { international law }\end{array}$ & Annex $1 /$ Annex $2 /$ non-Annex 1 \\
\hline & Pragmatism & Obligations versus morale & $\begin{array}{l}\text { Let each national parliament } \\
\text { (or equivalent) decide } \\
\text { whether proportional or } \\
\text { conceptual HR is preferred }\end{array}$ \\
\hline
\end{tabular}

\section{THE SCIENCE-POLICY INTERFACE ON HISTORICAL RESPONSIBILITY}

The science of HR, particularly proportional definitions, has often been acknowledged in the UNFCCC process. The first time an elaborated proposal to differentiate responsibilities in proportion to countries' contributions to climate change was mentioned in the official UNFCCC documentation was in 1996. In preparing the Kyoto Protocol, a 'compilation of information"74 included a summary of a report by Grüebler and Nakićenović75 that elaborated on the possibility of emissions 'cutbacks proportional to past contributions to atmospheric concentration increase'. Soon after, the Brazilian government filed their version of proportional HR, representing the first time a Party coherently proposed how proportionality could be quantified. ${ }^{37}$

The Brazilian government engaged several Brazilian experts to draft their proposal, assisted by experts from outside Brazil. Sanctioned by the UNFCCC's Subsidiary Body for Scientific and Technological Advice (SBSTA), Brazil organized workshops that initiated an era of negotiating scientific and methodological details of the proposal. The proposal became a standing item on SBSTA's agenda for almost 10 years (1998-2008).

As there is no sign that the issue of HR will disappear from the UNFCCC agenda, defining more precisely what the concept means may be important in the coming years of negotiating how to differentiate responsibilities for the 2020 regime. Following decision $1 / C P .16^{76}$ of the Conference of 
the Parties (COP) to the UNFCCC, adopted in Cancún 2010, the concept has been discussed even more thoroughly. The decision acknowledges that: 'the largest share of historical global emissions of GHGs originated in developed countries and that, owing to this historical responsibility, developed country Parties must take the lead in combating climate change and the adverse effects thereof' ( $p$. 8). Unlike the Convention, this COP decision explicitly and for the first time in the history of the UNFCCC establishes HR as a valid concept endorsed by a plenary consensus. The decision also explicitly links HR to historical emissions. It does not, however, specify whether the link between past emissions and current responsibility should be understood proportionally or conceptually. To 'take the lead' can be, and is, understood both as quantifying proportional responsibility and as advocating a conceptual view in which responsibilities are quantified based on other criteria.

The decision gives limited opportunities for opponents of proportional HR to reject the concept by referring to the lack of HR as a guiding principle under the UNFCCC. Parties that had previously refrained from using the term, or voiced outright opposition to it, have now started to inscribe it in connection with a more conceptual operationalization. The 2012 LCA chair neatly summarizes the current diversity of views ${ }^{77}$ :

For some, historical responsibility was central to the discussions on a formulaic [proportional] approach, and this issue has to be resolved in terms of responsibility for current impacts before discussing the responsibility of non-Annex I Parties. For others, it was not seen as an adequate measure of equity because it is complex, static and includes a large number of variables. Furthermore, the world has changed and a Party's contributions are dynamic, not fixed as assumed by historical responsibility. (pp. 11-12)

There are many views in the UNFCCC process as to whether proportional HR should be an evolutionary or static concept, simple or complex, or whether it should be replaced by a conceptual understanding. The policy process reflects the full breadth of the scientific literature on HR. ${ }^{78}$

\section{Is further scientific guidance to UNFCCC politics on historical responsibility necessary?}

The complexities involved in defining historical responsibility indeed make it attractive for policymakers to encourage the scientific community to narrow down the options before making any further decisions. However, science is not always in a good position to do so. In other instances of environmental politics, ${ }^{79,80}$ science has proven itself able to conceal questions of politics under complex and technical language. Following a set of technical workshops organized by the UNFCCC Secretariat and a mandate by the SBSTA for the scientific community to give advice on the Brazilian proposal, this is also, at least to some extent, what happened with HR for a number of years in UNFCCC politics (1998-2008). ${ }^{81}$

Responding to the call from SBSTA, the scientific community indeed succeeded in clarifying the scope of the conflict in UNFCCC politics. It is our hope that this review has further clarified this scope. However, science has largely failed in narrowing down the options within this scope. We will address what both of these aspects mean for the science-policy interface of contemporary UNFCCC politics regarding $H R$.

We argue that the failure of the scientific community to narrow down the options was unavoidable from the start of negotiations. Three interconnected reasons explain why scientists cannot 'speak 
truth to power ${ }^{82}$ on the matter of HR: 1) the distribution of responsibilities hinges largely on perceptions of justice, and we lack universally accepted moral principles that underpin any clear-cut distributive scheme; 2) a deep ideological clash between traditional ways of framing climate change in developed and developing countries; and 3) UNFCCC negotiating practice.

Concerning the last of these points, UNFCCC negotiating practice: The ability of science to resolve controversy must be understood in a context in which policymakers engaged in the UNFCCC process must reach consensus. ${ }^{83}$ For scientists to successfully narrow down the options, they need to convince not just a majority of negotiators, but all negotiators that their short-list is to be preferred over others. Without a mandate from the UNFCCC to focus on either a conceptual or a proportional version of $\mathrm{HR}$ (to begin with), this task is, strictly speaking, impossible.

This dead end relates to the second of the points raised above, concerning traditional ways of framing climate change in developed and developing countries. ${ }^{84,85}$ One of the core tasks of the UNFCCC is to distribute responsibilities for taking measures in response to climate change. Developed countries have long argued that climate change is of such urgency that response measures must focus on the common responsibility of states, and that differentiation of responsibilities primarily entails taking different national capabilities and circumstances into account. From this perspective, the urgency of reducing global GHG emissions in light of the agreedon $2^{\circ} \mathrm{C}$ goal makes proportional HR less relevant, or even an obstacle to progress. Meeting the $2^{\circ} \mathrm{C}$ goal requires that all countries do whatever they can to reduce global emissions and increase adaptive capacities. HR could then, for example, be reflected in support provided to help developing countries pay for these efforts, beyond what they can themselves. This framing of climate change points more to a conceptual operationalization of HR as something that could help current global negotiations move forward on the issue. However, history has shown that conflict over how to define HR in the UNFCCC context is not resolved by some Parties', mostly developed, arguing that HR is already accounted for through the division of Parties into annexes with different responsibilities attached to them.

Developing countries have generally preferred a different framing of climate change. They have situated climate change in the context of an unequal world system. International climate negotiations should, through this lens, not only address environmental problems identified as urgent but should also seek to balance inequities and address underdevelopment. From this perspective, proportional HR makes better sense, as it is viewed as an equitable basis for reallocating the overexploitation of the atmosphere by developed countries. Proportional HR is addressed through a 'formulaic' approach, i.e., an approach in which efforts to respond to climate change are quantified by applying certain equity formulae. Many developing countries have stressed that a formulaic approach, in their mind properly addressing HR, is the foundation for rather than an obstacle to more effective global climate policy. The argument is that addressing climate change equitably will increase willingness to ratify and implement agreements. However, history has shown that such an approach, like the conceptual one, is very unlikely to succeed in generating support from all Parties. If the history of HR has taught us anything, in fact, one of its strongest lessons is that policymakers will not easily give in to one another's positions on HR in the foreseeable future.

These differences in perspective run deep and seem fundamental. If scientists speak of one but not another version, they have been and will likely continue to be met with suspicion and even distrust 
among some policymakers and with cheers among others. Further to this situation, point one raised above speaks to the fact that neither policymakers nor scientists - the latter having been thoroughly examined in this review - agree on what constitutes a fair, morally justifiable, and universally agreeable distribution of responsibilities to act on climate change. ${ }^{86,87}$ Although many researchers engaged in discussing conceptual HR have the explicit ambition to propose morally justifiable approaches to HR, most of the researchers debating proportional HR aim to lay out the options among which politicians can choose. The sheer complexity involved in defining HR, however, leads to implicit positioning in this political debate by laying out some options and not others. This fact informs our discussion of the impossibility of science narrowing down options when scientists themselves do not agree whether HR should be understood conceptually or proportionally - to mention only the most fundamental divergence of perspectives described here. HR is simply not natural science, no matter whether simple climate models or moral philosophy are used to define the concept.

The science has definitely - probably much against many scientists' best intentions to be as objective as possible - become a tool in the ideological quarrels among UNFCCC policymakers. In fact, although many scientists have striven to depoliticize HR and narrow down the options to a list of possibilities that they deem scientifically preferable, they are in fact - consciously or unconsciously being political. This situation may not reflect how science-policy interactions generally operate, but it is indeed the reality facing the scientists currently interacting with policymakers in the case of HR. In short, science has failed to resolve ideological controversy concerning HR.

That being said, science has indeed succeeded in clarifying the scope of the conflict in the UNFCCC. After at least 10 years of thorough scientific investigation, the scope has proven to be very large. Although this process has not been marked by a narrowing down of options, but rather has opened up the full range of possibilities, the complexities involved should now be sufficiently clear to enable policymakers to engage in the next phase of HR negotiation.

In this context, a critical scientific review of the usefulness of the HR approach in negotiations of a future international climate regime is nearly futile. The ideological differences between states cannot be resolved through science. The roots of UNFCCC controversy over HR are much too deep to be instrumentally resolved through science - indeed, the opposite is the case. Instead, we propose that a review of the present kind can lead to only one clear conclusion of relevance to the sciencepolicy interface: If science is to play another role than illuminating and expanding on the complexities involved in defining HR, scientists need clearer guidance from policy circles.

UNFCCC negotiating practice allows all Parties to the UNFCCC to draw on all the aspects articulated in the literature when developing positions on HR. This scientific complexity is not an excuse to avoid using proportional or conceptual versions of $\mathrm{HR}$ to operationalize equity, even if they could be used for such a purpose. However, it does indicate at least one important lesson for the UNFCCC process: Since the various defining aspects of HR are numerous and often in conflict, it is inherently impossible to arrive at consistent and unambiguous scientific policy advice. Referring the issue to the scientific community would likely only result in postponing much-needed dialogue between entrenched positions in the UNFCCC - unless policymakers first agree on a clearer understanding of how HR should be anchored in existing treaties through future agreements. With clearer guidance in the form of a more focused agreement on HR in the UNFCCC, we trust that the scientific community 
will have the capacity to provide clearer options for understanding and operationalizing HR in the UNFCCC.

Should negotiators drop proportional as well as conceptual HR altogether? We do not think so. In any case, our opinion will not likely affect the fact that this is not going to happen in the foreseeable future. We do, however, believe that HR is important precisely because it touches on differences in opinion on climate change between states. Ignoring this will not resolve long-term issues in climate policy; continuing to build mutual understanding and to learn from each other, however, could steer states' perceptions of climate change in the direction of common understandings.

\section{Conclusion}

In the literature, it is possible to track a wide range of aspects to consider when defining historical responsibility (HR) for climate change (see Table 1 ). However, the inventory provided here is not intended to hold HR hostage to complexity. As with other issues, policymakers and scientists should make informed choices as best they can. However, the scientific complexity of assigning HR offers at least one important lesson to the UNFCCC process: Assigning HR entails choosing among many defining aspects, making it virtually impossible to arrive at simple scientific policy advice.

While the argument for HR is still strong in principle, establishing a causal link between past emissions and current responsibilities is complicated by the sheer number of often incompatible defining aspects of HR. On the other hand, a conceptual version of HR in which operationalization centers on, for example, capacity to act would imply new problems in constructing a model to characterize capacity. Who has the needed capacity and to what degree this implies responsibility are questions for another literature struggling with models of level of development and wellbeing, sometimes overlapping with models of the assignment of $\mathrm{HR}^{15}$

The scientific community has developed many tools for establishing a proportional link between contributions and responsibilities. Similarly, the literature on establishing a conceptual link between historical contributions and responsibilities to act is growing. Yet any attempt to operationalize the link will have little relevance to policy unless policymakers agree on a framework for quantifying such responsibilities.

The fact that COP, in late 2010, agreed to inscribe HR as relevant to differentiating responsibilities in any future development of the UNFCCC regime indicates its growing recognition in UNFCCC politics. This makes it all the more important to understand the diverse aspects involved in defining the concept of HR. In general, it can be concluded that, as the climate regime is developing into a bottom-up and soft-law architecture, a proportional definition of $\mathrm{HR}$, based as it is on a formulaic approach to equity, is developing into a more radical position. A formulaic approach is much more easily reconciled with the Kyoto Protocol's design of an aggregated target to be equitably shared by Parties with commitments (Annex B). Given that the climate regime architecture is moving away from a top-down and command-and-control (i.e., hard law) approach, towards a more bottom-up and 'pledge-and-review' (i.e., soft law) approach, advocating a proportional understanding of HR becomes much more an act in opposition to, rather than in reconciliation with, the regime's overall development trajectory. However, this is not the same as saying that proportional HR is becoming irrelevant. The conflict between proponents of proportional versus conceptual understandings of HR 
may indeed intensify in the future, as stakes are growing higher, requirements for adaptation are increasing, and the mitigation window to keep below $2^{\circ} \mathrm{C}$ warming is closing.

A review of this kind of course begs the question of whether some means of identifying HR are better, more useful, and/or more politically feasible than others. We hope we have demonstrated that the advantages of one definition over another depend on the criteria by which the beholder is judging HR. Science can indeed help policymakers identify better versions of HR if fundamental differences in perspectives have first been resolved. As long as policymakers disagree along fundamental lines, and as long as each Party to the UNFCCC effectively has a veto in the negotiating process, scientific advice can serve to fuel the debate. Throwing such coal on the fire can indeed benefit the democratic debate. Science has done an excellent job of identifying the full range of possible positions on $\mathrm{HR}$, and of clarifying the differences between them, but it cannot demonstrate which is a fairer or more correct approach to defining HR. If policymakers want further advice from the scientific community, it is time that they first answered the question: About what do we want advice?

\section{Acknowledgement}

We express our gratitude to the Swedish Research Council on Environment, Agricultural Sciences and Spatial Planning (Formas) for funding this research. We also thank the anonymous reviewers as well as colleagues at the Centre for Climate Science and Policy Research for providing muchappreciated comments on previous versions of this manuscript.

\section{References}

1. UN. INC1: Report, Washington, 1991. A/AC.237/6. 1991. Available at: http://www.unfccc.int

2. UN. INC5, Part I: Report, New York, 1992. A/AC.327/18 (Part I). 1992, Page 10 26. Available at: http://www.unfccc.int

3. Caney S. Environmental Degradation, Reparations, and the Moral Significance of History. Journal of Social Philosophy 2006, 37:464-482.

4. Caney S. Cosmopolitan Justice, Responsibility, and Global Climate Change. Leiden Journal of International Law 2005, 18:747-775.

5. Halme P. Carbon Debt and the (In) Significance of History. TRAMES 2007, 11:346-365.

6. Meyer LH. Compensating Wrongless Historical Emissions of Greenhouse Gases. Ethical Perspectives 2004, 11:20-35.

7. Garvey J. The Ethics of Climate Chnage: right and wrong in a warming world. New York: Continuum; 2008.

8. den Elzen M, Schaeffer M, Lucas PL. Differentiating future commitments on the basis of countries' relative historical responsibility for climate change: Uncertainties in the 'Brazilian proposal' in the context of a policy implementation. Climatic Change 2005, 71:277-301.

9. den Elzen $M$, Schaeffer M. Responsibility for past and future global warming: Uncertainties in attributing anthropogenic climate change. Climatic Change 2002, 54:29-73.

10. Höhne N, Moltmann S. Distribution of emission allowances under the Greenhouse Development Rights and other effort sharing approaches. 2008.

11. Müller B, Höhne N, Ellermann C. Differentiating (Historic) Responsibilities for Climate Change: Summary Report. 2007.

12. Trudinger $C$, Enting I. Comparison for formalism for attributing responsibility for climate change: Non-liniarities in the Brazilian proposal approach. Clmatic Change 2005, 68:67-99. 
13. Muylaert de Araujo MS, de Campos CP, Pinguelli Rosa L. GHG historical contribution by sectors. Renewable and Sustainable Energy Reviews 2005:1-10.

14. Obama BH. Transcript: President Obama Delivers Remarks at 2009 G8 Summit, L'Aquila, Italy. The Washington Post 2009.

15. Baer P, Athanasiou T, Kartha S, Kemp-Benedict E. The Greenhouse Development Rights Framework: The right to development in a climate constrained world. Berlin: Heinrich Böll Stiftung, EcoEquity, Christian Aid and the Stockholm Environment Institute; 2008.

16. UNFCCC. SBSTA14: Progress report on the review of the scientific and methodological aspects of the proposal by Brazil. FCCC/SBSTA/2001/INF.2. 2001.

17. Höhne N. What is Next After the Kyoto Protocol? Assessment of Options for International Climate Policy post 2012. Amsterdam: Techne Press; 2006.

18. Neumayer E. In defence of historical accountability for greenhouse gas emissions. Ecological Economics 2000, 33:185-192.

19. den Elzen M, Berk M, Schaeffer M, Olivier J, Hendriks C, Metz B. The Brazilian Proposal and other options for international burden sharing: An evaluation of methodological and policy aspects using the FAIR model. 1999.

20. Jagers SC, Duus-Otterström G. Dual climate change responsibility: on moral divergences between mitigation and adaptation. Environmental Politics 2008, 17:576-591.

21. Dellink R, den Elzen M, Aiking H, Bergsma E, Berkhout F, Dekker T, Gupta J. Sharing the burden of financing adaptation to climate change. Global Environmental Change 2009, 19:411-421.

22. Jagers SC, Duus-Otterström G. Intergenerational Responsibility: Historical Emissions and Climate Change Adaptation. QoG WORKING PAPER SERIES 2007.

23. Thompson J. Taking Responsibility for the Past: Reparation and Historical Injustice. Cambridge and Malden: Polity; 2002.

24. Shine KP, Fuglestvedt JS, Hailemariam K, Stuber N. Alternatives to the Global Warming Potential for Comparing Climate Impacts of Emissions of Greenhouse Gases Climatic Change 2005, 68:281-302.

25. Fuglestvedt JS, Berntsen TK, Godal O, Sausen R, Shine KP, Skodvin T. Metrics of Climate Change: Assessing Radiative Forcing and Emissions Indices. Climatic Change 2003, 58:267331.

26. den Elzen M, Fuglestvedt J, Höhne N, Trudinger C, Lowe J, Matthews B, Romstad B, de Campos $\mathrm{CP}$, Andronova N. Analysing countries' contribution to climate change. Environmental Science and Policy 2005, 8:614-636.

27. den Elzen $M$, Schaeffer $M$. Assesment of major uncertenties in calculating regional contributions to climate change. 2002.

28. La Rovere EL, de Macedo LV, Baumert KA. The Brazilian Proposal on Relative Responsibility for Global Warming. In: Baumert KA, ed. Building on the Kyoto Protocol: Options for Protecting the Climate: World Resource Institute; 2002, 157-174.

29. Botzen WJW, Gowdy JM, Bergh JCJMvd. Cumulative CO2 emissions: shifting international responsibilities for climate debt Climate Policy 2008, 8:569-576.

30. Sagar AD. Wealth, responsibility and equity: Exploring an allocation framework for global GHG emissions. Climatic Change 2000, 45:511-527.

31. Harvey LDD. Global warming: the hard science. Harlow: Prentice-Hall; 2000.

32. Höhne N, Blok K. Calculating historical contribututions to climate change. Climatic Change 2005, 71:141-173.

33. Höhne N, Harnisch J. Evaluating indicators for the relative responsibility for climate change; alternatives to the Brazilian proposal and GWPs. Third International Symposium on Non-CO2 Greenhouse Gases (NCGG-3) 2003. 
34. Meira Filho LG, Miguez JDG. UNFCCC technical Note: Note on the Time-Dependent Relationship between Emissions of Greenhouse Gases and Climate Change. Available at: http://unfccc.int/resource/brazil/documents/proposta.pdf.

35. Andronova N, Schlesinger M. Importance of Sulfate Aerosol in Evaluating the Relative Contributions of Regional Emissions to the Historical Global Temperature Change. Mitigation and Adaptation Strategies for Global Change 2004, 9:383-390.

36. Muylaert MS, Cohen C, Pinguelli Rosa L, Pereira SA. Equity, responsibility and climate change. Climate Research 2004, 28:89-92.

37. UNFCCC. AGBM7: Implementation of the Berlin Mandate: Additional proposals from Parties. FCCC/AGBM/1997/MISC.1/Add.3. 1997. Available at:

file://L:\%5CHistorisk\%20skuld\%5CK\%E4llor\%5CAGBM\%5CAGBM_007\%20\%20ORIGINAL\%20BRAZILIAN\%20PROPOSAL.pdf

38. Ball RH. Discussion Paper for the UNFCCC Experts Meeting on the Brazilian Proposal. UNFCCC workshop 2001.

39. UNFCCC. SBSTA17: Scientific and Methodological Assessment of Contribution to Climate Change: Report of the Expert Meeting. FCCC/SBSTA/2002/INF.14. 2002.

40. Enting I. Attribution of greenhouse gas emissions, concentrations and radiative forcing. CSIRO Atmospheric Research Technical Paper No. 381998.

41. den Elzen $M$, Schaeffer $M$, Eickhout $B$. Responsibility for past and future global warming: time horizion and non-linerarities in the climate system. 2002.

42. Andronova N, Schlesinger M. Evaluation of the Relative Contributions of the Regional Emissions by Annex I and Non-Annex I to the Historical Global Temperature Change. 2002.

43. de Campos CP, Muylaert MS, Rosa LP. Historical CO2 emission and concentrations due to land use change of croplands and pastures by country. Science of The Total Environment 2005, 346:149-155.

44. Muylaert de Araújo MS, Silvab C, Camposc CPd. Land use change sector contribution to the carbon historical emissions and the sustainability: Case study of the Brazilian Legal Amazon. Renewable and Sustainable Energy Reviews 2009, 13:696-702.

45. Martinez-Alier J. Ecological Debt and Property Rights on Carbon Sinks and Reservoirs. Capitalism Nature Socialism 2002, 13:115-119.

46. Muylaert de Araujo MS, Campos CPd, Pinguelli-Rosa L. Historical emissions, by country, of $\mathrm{N} 2 \mathrm{O}$ from animal manure management and of $\mathrm{CH} 4$ from enteric fermentation in domestic livestock. Climate Research 2007, 34:253-258.

47. Andres RJ, Fielding DJ, Marland G, Boden TA, Kumar N, Kearney AT. Carbon dioxide emissions from fossil-fuel use, 1751-1950. Tellus B 1999, 51:759-765.

48. Pinguelli-Rosa L, Ribeiro SK, Muylaert MS, de Campos CP. Comments on the Brazilian Proposal and contributions to global temperature increase with different climate responses: $\mathrm{CO} 2$ emissions due to fossil fuels, $\mathrm{CO} 2$ emissions due to land use change. Energy Policy 2004, 34:1499-1510.

49. Oberheitmann A. A new post-Kyoto climate regime based on per-capita cumulative CO2emission rights: rationale, architecture and quantitative assessment of the implication for the CO2-emissions from China, India and the Annex-I countries by 2050. Mitigation and Adaptation Strategies for Global Change 2010, 15:137-168.

50. Ellermann C, Höhne N, Müller B. Differentiating historical responsibilities for climate change. In: Harris PG, ed. China's responsibility for climate change: Ethics, fairness and environmental policy. Bristol: The Policy Press; 2011, 71-98.

51. Lenzen M, Dey CJ, Murray SA. Historical accountability and cumulative impacts: the treatment of time in corporate sustainability reporting. Ecological Economics 2004, 51:237250.

52. Schüssler R. Climate justice: a question of historic responsibility? Journal of Global Ethics 2011, 7:261-278. 
53. Gosseries A. Historical Emissions and Free-Riding. Ethical Perspectives 2004, 11:36-60.

54. Gardiner SM. Ethics and climate change: an introduction. WIREs Climate Change 2010, 1:5466.

55. Shue H. Global environment and international inequality. International Affairs 1999, 75:531545.

56. Simms A. An Environmental War Economy: the lessons of ecological debt and global warming. London New Economics Foundation; 2001.

57. Grubb M, Sebenius J, Magalhaes A, Subak S. Sharing the Burden. In: Mintzer IM, ed. Confronting Climate Change: Risks, Implications and Responses. Cambridge: Cambridge University Press; 1992, 305-322.

58. Pinguelli-Rosa L, Ribeiro SK. The Present, Past, and Future Contributions to Global Warming of $\mathrm{CO} 2$ Emissions from Fuels: A Key for Negotiation in the Climate Convention. Climatic Change 2001, 48:289-308.

59. Müller B, Höhne N, Ellermann C. Differentiating (Historic) Responsibilities for Climate Change: Summary Report. Climate Policy 2009, 9:593-611.

60. Rive N, Fuglestvedt J. Introducing population-adjusted historical contributions to global warming Global Environmental Change 2008, 18:142-152.

61. Guoquan H, Yong L, Hongbin L. Contributions of Accumulative Per Capita Emissions to Global Climate Change. In: Sciences CAo, ed. Carbon equity: Perspectives from Chinese academic community. Tsinghua: Chinese Academy of Sciences; 2009, 1-6.

62. Oberheitmann A, Sternfeld E. Global governance, responsibility and a new climate regime. In: Harris PG, ed. China's responsibility for climate change: Ethics, fairness and environmental policy. Bristol: The Policy Press; 2011, 195-220.

63. Pan J, Phillips J, Chen Y. China's balance of emissions embodied in trade: approaches to measurement and allocating international responsibility. Oxford Review of Economic Policy 2008, 24:354-376.

64. Peters GP, Hertwich EG. CO2 Embodied in International Trade with Implications for Global Climate Policy. Environmental Science and Technology 2008, 42:1401-1407.

65. Steckel JC, Kalkuhl M, Marschinski R. Should carbon-exporting countries strive for consumption-based accounting in a global cap-and-trade regime? Climatic Change 2010, 100:779-786.

66. Agarwal A, Narain S. Global warming in an unequal world: a case of environmental colonialism. 1991.

67. Agarwal A, Narain S, Sharma A, Imchen A, eds. Poles Apart. New Delhi: Centre for Science and Environment; 2001.

68. Barrett S. 'Acceptable' allocations of tradeable carbon emission entitlements in a global warming treaty. In: UNCTAD, ed. Combating Global Warming-Study on a Global System of Tradeable Carbon Emissions Entitlements. New York: UN; 1992, 85-113.

69. Beckerman W, Pasek J. The equitable international allocation of tradable carbon emission permits. Global Environmental Change 1995, 5:405-413.

70. Jacoby HD, Schmalensee R, Wing IS. Toward a Useful Architecture for Climate Change Negotiations. MIT Joint Program on the Science and Policy of Global Change 1999, Pages 124.

71. Mickelson K. Beyond a politics of the possible? South-North relations and climate justice. Melbourne Journal of International Law 2009, 10:411-423.

72. Winkler H, Jayaraman T, Pan J, Oliveira ASd, Zhang Y, Sant G, Miguez JDG, Letete T, Marquard A, Raubenheimer S. Equitable access to sustainable development: Contribution to the body of sceintific knowledge. 2011.

73. Rajamani L. The Principle of common but differentiated responsibilities and the balance of commitments under the climate regime. RECIEL 2000, 9:120-131. 
74. UNFCCC. AGBM3: Annotated compilation of information relevant to the Berlin Mandate process. FCCC/AGBM/1996/3. 1996.

75. Grübler A, Nakićenović N. International burden sharing in greenhouse gas reduction. 1992.

76. UNFCCC. COP16: Report (addendum 1), including desicion 1/CP.16, Cancún 2010. FCCC/CP/2010/7/Add.1. 2011.

77. UNFCCC. AWG-LCA15_02: Report on the workshop on equitable access to sustainable development. FCCC/AWGLCA/2012/INF.3/Rev.1. 2012.

78. Friman M. Historical responsibility: Assessing the past in international climate negotiations. Department of Thematic Studies 2013. Vol. Linköping Studies in Arts and Sceince No. 569.

79. Sarewitz D. How science makes environmental controversies worse. Environmental Science and Policy 2004, 7:385-403.

80. Lövbrand E. Pure sceince or policy involvement? Ambiguous boundary-work for Swedish carbon cycle sceince. Environmental Science and Policy 2007, 10:39-47.

81. Friman $\mathrm{M}$, Linnér B-O. Technology obscuring equity: historical responsibilities in UNFCCC negotiations. Climate Policy 2008, 8:339-354.

82. Oreskes N. Science and public policy: what's proof got to do with it. Environmental Science and Policy 2004, 7:369-383.

83. Brunnée J. COPing with Consent: Law-Making Under Multilateral Environmental Agreements. Leiden Journal of International Law 1-52 (2002) 2002, 15:1-52.

84. Linnér B-O, Jacob M. From Stockholm to Kyoto: A Review of the Globalization of Global Warming Policy and North-South Relations. Globalizations 2005, 2:403-415.

85. Selin H, Linnér B-O. The Quest for Global Sustainability: International Efforts on Linking Environment and Development. CID Graduate Student and Postdoctoral Fellow Working Paper No. 52005.

86. Linnerooth-Bayer J. Climate Change and Multiple Views of Fairness. In: Tóth FL, ed. Fair Weather? Equity Concerns in Climate Change. London: Earthscan; 1999, 44-64.

87. Ikeme J. Equity, environmental justice and sustainability: incomplete approaches in climate politics. Global Environmental Change 2003, 13:195-206.

Further Reading

Okereke, C. Climate justice and the international regime. WIREs Climate Change 2010, 1:462-474.

UNFCCC. Scientific and Methodological Assessment of Contributions to Climate Change. Available at: http://unfccc.int/methods_and_science/other_methodological_issues/items/1038.php 